Article

\title{
Farm Level Assessment of Irrigation Performance for Dairy Pastures in the Goulburn-Murray District of Australia by Combining Satellite-Based Measures with Weather and Water Delivery Information
}

\author{
Mohammad Abuzar 1,* (D), Des Whitfield ${ }^{2}$ and Andy McAllister ${ }^{2}$ \\ 1 Agriculture Victoria Research, Department of Economic Development, 32 Lincoln Sq N, \\ Carlton 3053, Victoria, Australia \\ 2 Agriculture Victoria Research, Department of Economic Development, 255 Ferguson Road, Tatura 3016, \\ Victoria, Australia; des.whitfield@ecodev.vic.gov.au (D.W.); andy.mcallister@ecodev.vic.gov.au (A.M.) \\ * Correspondence: mohammad.abuzar@ecodev.vic.gov.au
}

Academic Editors: Tao Cheng, Eugene Genong Yu and Wolfgang Kainz

Received: 28 June 2017; Accepted: 2 August 2017; Published: 6 August 2017

\begin{abstract}
Pasture performance of 924 dairy farms in a major irrigation district of Australia was investigated for their water use and water productivity during the 2015-2016 summer which was the peak irrigation period. Using satellite images from Landsat- 8 and Sentinel-2, estimates of crop coefficient $(\mathrm{Kc})$ were determined on the basis of a strong linear relationship between crop evapotranspiration (ETc) and vegetation index (NDVI) of pasture in the region. Utilizing estimates of Kc and crop water requirement (CWR), NDVI-dependent estimates of Irrigation Water Requirement (IWR) were derived based on the soil water balance model. In combination with daily weather information and seasonal irrigation water supply records, IWR was the key component in the understanding of current irrigation status at farm level, and deriving two irrigation performance indicators: (1) Relative Irrigation Water Use (RIWU) and (2) Total Irrigation Water Productivity (TIWP). A slightly higher proportion of farm irrigators were found to be either matching the irrigation requirement or under-watering (RIWU $\leq 1.0)$. According to TIWP, a few dairy farms $(3 \%)$ were found to be in the category of high yield potential with excess water use, and very few (1\%) in the category of limited water supply to pastures of high yield potential. A relatively high number of farms were found to be in the category where excess water was supplied to pastures of low-medium yield potential $(27 \%)$, and farms where water supply compromised pastures with a sub-maximal vegetation status $(15 \%)$. The results of this study will assist in objectively identifying where significant improvement in efficient irrigation water use can be achieved.
\end{abstract}

Keywords: irrigation water requirement; irrigation performance indicators; soil water balance

\section{Introduction}

Irrigated agriculture is the major consumer of freshwater worldwide, presently in the order of about $70 \%$ [1,2]. However, water availability for agriculture continues to decline due to competing demands from other sectors such as municipal, industrial, and recently environmental and recreational [1,3-5]. Assessment of irrigation performance is critically important for improving irrigation water management and the sustainability of irrigated agriculture [6]. To measure irrigation performance, numerous indicators have been suggested and evaluated [3-5,7-10]. The key parameters used in most of these indicators include crop water use, crop water supply and crop productivity.

There has been a long tradition of measuring crop water use and crop water requirement to assess irrigation performance. A 1977 FAO publication [11] related crop water use (ETc, crop 
evapotranspiration) to reference evapotranspiration (ETo) and crop coefficient (Kc), which account for all crop-specific variables: ETc $=$ Kc.ETo. Later on, in order to maintain consistency, standard procedures were developed and introduced to calculate Kc and ETo in a paper 'FAO56' in 1998 [12], which have been widely adopted [13]. Kc values calculated by traditional methods [12] represent average to optimum crop status under stress-free conditions and fail to describe variations within and across fields [14]. On the other hand, actual Kc estimates present inherent variations arising out of physical, physiological and management factors. Recent approaches using remote sensing techniques overcome these shortcomings of traditional Kc values $[5,8,14-16]$ and make it possible to have fieldand time-specific actual Kc estimates [8].

There are three broad approaches that use remote sensing techniques to estimate $\mathrm{Kc}$ as described below.

(1) 'ET Analytical (ETA) Approach' is used to estimate ET directly by using Penman-Monteith equation as adopted in 'FAO56' [17]. To calculate ETc, this approach requires certain biophysical crop parameters such as albedo ( $\mathrm{r}$-dimensionless), Leaf Area Index $\left(\mathrm{LAI}-\mathrm{m}^{2} / \mathrm{m}^{2}\right)$, estimated from satellite images. Then in combination with meteorological data, Kc can be calculated as ETc/ETo ratio $[17,18]$. This approach does not require thermal infrared waveband but does require visible, near-infrared (NIR) and shortwave infrared (SWIR) bands.

(2) 'Surface Energy Balance (SEB) Approach' provides instantaneous actual ET estimates [19,20]. This approach is based on the relationship of various energy fluxes $(\mathrm{Rn}=\mathrm{LE}+\mathrm{H}+\mathrm{G})$. The net energy flux $(\mathrm{Rn})$ is distributed between soil heat flux $(\mathrm{G})$ and convective fluxes (sensible heat flux, H, and latent heat flux, LE). LE can be determined as residual energy if the other fluxes are known, measured or modelled. The 2 residual energy methods that are widely used are (1) Surface energy balance algorithm for land (SEBAL) [20], and (2) Mapping evapotranspiration at high resolution and with internalised calibration (METRIC) [16]. Actual ET values from this approach can then be used to calculate actual Kc estimates for specific fields and crops [21]. This approach essentially requires thermal infrared wavebands in addition to visible, NIR and SWIR bands.

(3) 'ET-Vegetation-Relationship (ETVR) Approach' is based on the strong physical correspondence between crop evapotranspiration and the spectral response of vegetation, with particular reference to the visible and NIR spectral regions [21-23]. Reflectance measurements in the red and NIR, are used to derive, through simply linear combination, some spectral vegetation indices (e.g., NDVI) and then the values of NDVI are utilized to calculate the crop coefficient through a linear relationship between NDVI and $K_{c}\left(K_{c}=a \cdot N D V I \pm b\right)$. Once the ET-vegetation relationships are established for specific crops and specific region, this approach simply requires visible and NIR wavebands to calculate Kc on a routine basis.

The ETVR approach has an obvious advantage of wider application as it requires minimum satellite data (red and NIR wavebands) as compared to the other two approaches (ETA and SEB). A number of studies have shown the application of this approach to calculate actual Kc values for estimating crop water use [21-23]. However, there are very few studies that have combined this simple approach with soil water balance modelling in order to adequately determine irrigation water requirement (IWR) of crops [24,25]. Similar studies for pasture are scarce.

In this study, we present IWR for dairy pastures as estimated by using the ETVR approach combined with soil water balance modelling. We demonstrate the use of IWR thus estimated for the two key indicators for assessing irrigation performance. The two key performance indicators are: (1) Relative Irrigation Water Use (RIWU) and (2) Total Irrigation Water Productivity (TIWP). We demonstrate the application of the two indicators to assess water use and productivity of irrigated dairy farms for the peak irrigation (summer) period of 2015-2016 in the Goulburn-Murray Irrigation District (GMID) of Victoria. The nominated timeframe for this study was 1 December 2015 to 29 February 2016.

The GMID is located approximately between $35.28^{\circ} \mathrm{S}$ and $35.57^{\circ} \mathrm{S}$ latitudes, and between $143.76^{\circ} \mathrm{E}$ and $146.11^{\circ} \mathrm{E}$ longitudes in the State of Victoria, Australia (Figure 1). The average annual rainfall 
ranges between 300 and $500 \mathrm{~mm}$ with most of this falling during winter (June to August). Summer (December to February) is generally dry and when supplemental water for crops is most needed. The region is well known for horticulture and dairy production. Pastures in the study area are mostly a mix of white clover (Trifolium repens L.) and perennial ryegrass (Lolium perenne L.)

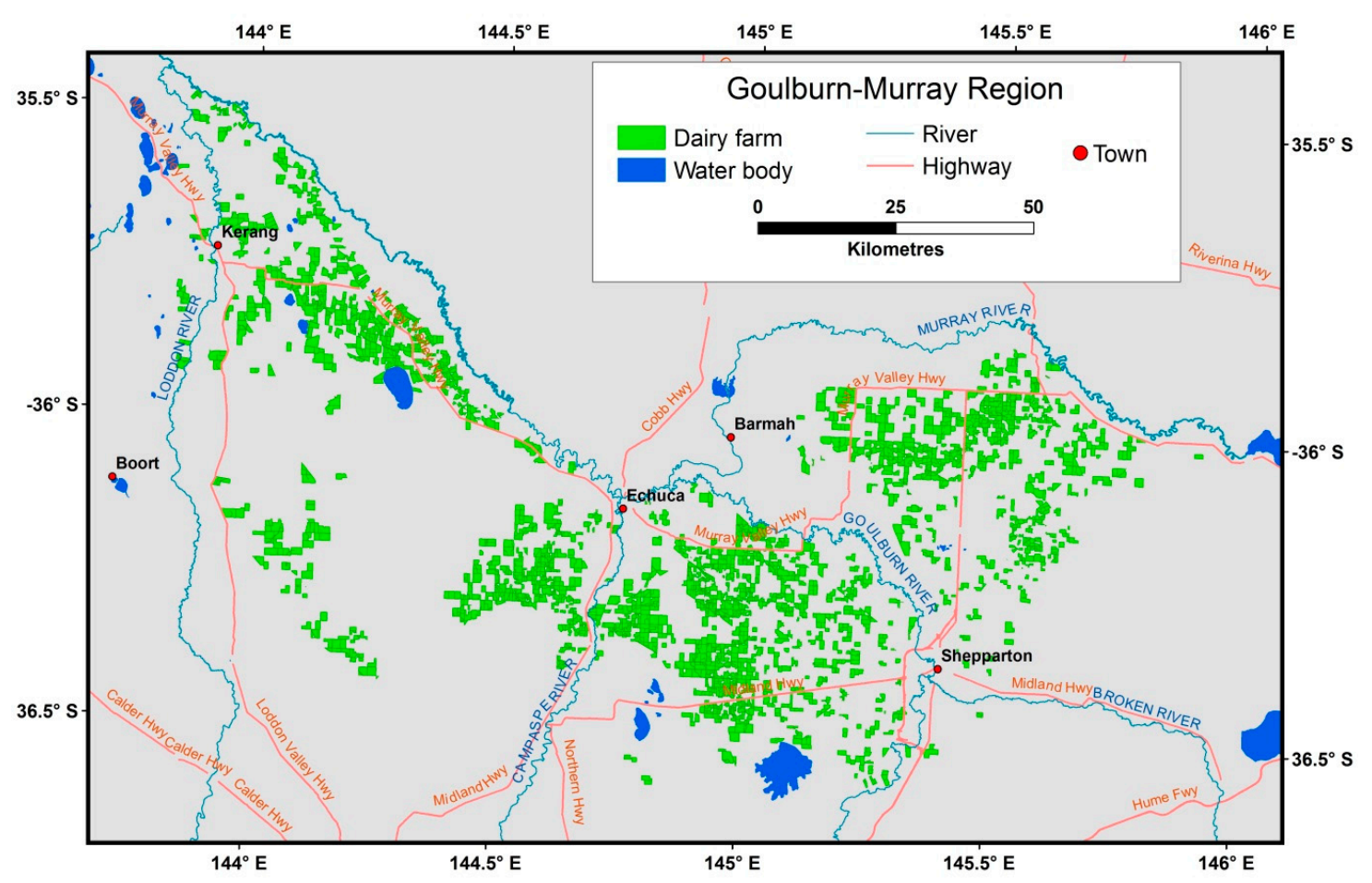

Figure 1. Location of dairy farms in the Goulburn-Murray Irrigation District.

\section{Materials and Methods}

The data sets and the processes required to calculate the parameters for the two irrigation performance indicators (RIWU, TIWP) are summarised in Figure 2. The key data sets included satellite imagery, daily weather information and irrigation water delivery records. In addition, pre-existing information on Kc profiles and land use details were also required. Weather information was downloaded from SILO website [26], including daily measures of maximum temperature, minimum temperature, rainfall, pan evaporation, solar radiation, vapor pressure, maximum relative humidity, minimum relative humidity, and FAO56 reference evapotranspiration. Farm water delivery information was sourced from the Victorian Water Register (VWR) [27]. Land use information on dairy properties was sourced from the current data set of the Victorian Land Use Information System (VLUIS) [28], which was based on the property valuation by the state government agency Valuer General Victoria (VGV). A Water Use Licence (WUL) unit, as defined within the VWR, was taken as the extent of a dairy farm. Only the larger (20 ha and above) dairy farms (924) have been selected for this study. 


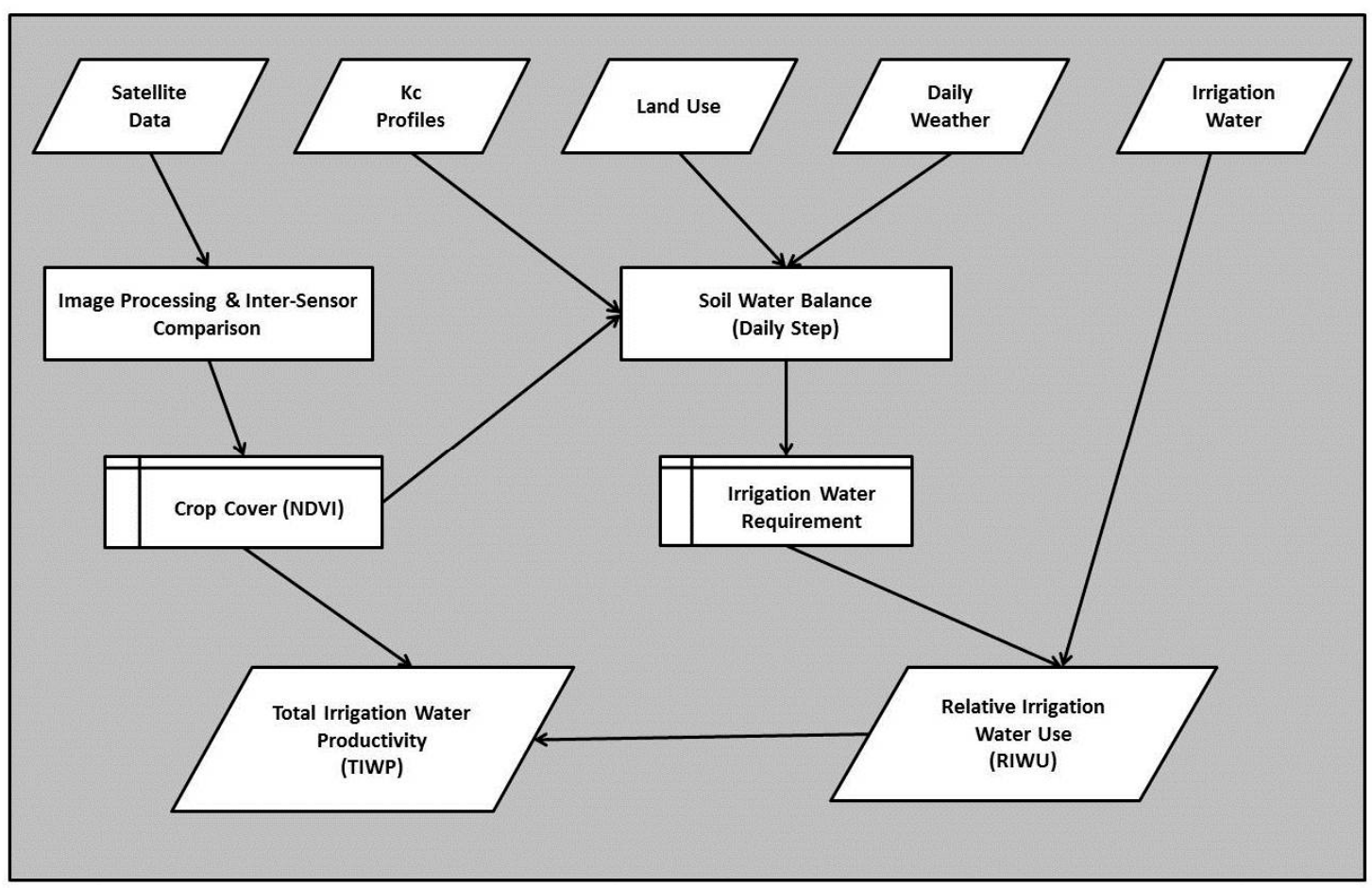

Figure 2. Flowchart showing derivation process of irrigation performance indicators.

\subsection{Satellite Data}

Cloud-free satellite images from Landsat- 8 and Sentinel-2A were acquired to represent the summer season, the period of maximum development of crop canopies in the study area (Table 1). Three sets of images were required to have a complete spatial coverage over the study area. Sentinel images were geocoded top-of-atmosphere (TOA) reflectance (Level-1C). Landsat images were converted into reflectance using standard procedure [29]. Reflectance values of red and near-infrared wavebands were used to calculate the Normalised Difference Vegetation Index (NDVI):

$$
\mathrm{NDVI}=(\mathrm{NIR}-\mathrm{R}) /(\mathrm{NIR}+\mathrm{R})
$$

NIR denotes near-infrared waveband referring to Landsat-8 Band-5 (845-886 nm) and Sentinel-2A Band-8 (780-910 nm). R denotes red waveband referring to Landsat-8 Band-4 (630-680 nm) and Sentinel-2A Band-4 (640-690 nm). To maintain consistency, Sentinel NDVI values were converted into Landsat-equivalent values using a separately established relationship (Figure 3): Y $=0.0862+0.9037 \mathrm{X}$.

Table 1. Satellite data used in this study.

\begin{tabular}{cccc}
\hline Acquisition Date & Satellite & Scene ID & Image Source \\
\hline 28 December 2015 & Sentinel-2A & T55HBA, T55HBV, T55HCA, & https://scihub.copernicus.eu/dhus/ \\
18 January 2016 & Landsat-8 & 094/084 and 094/085 & $\mathrm{http://earthexplorer.usgs.gov}$ \\
05 February 2016 & Landsat-8 & 092/085 & $\mathrm{http://earthexplorer.usgs.gov}$ \\
\hline
\end{tabular}

\subsection{Estimating Irrigation Water Requirement (IWR)}

Farm-scale estimates of IWR were made by calculating the additional amounts of water required to sustain a crop/pasture in an ideal, stress-free condition. IWR was calculated on the basis of NDVI-dependent crop evapotranspiration (ETc) estimates using 'short' crop reference evapotranspiration (ETo): 


$$
\mathrm{ETc}=\mathrm{Kc} \cdot \mathrm{ETo}
$$

For the calculation of ETo, the following equation was used:

$$
\mathrm{ETo}=(0.408 \mathrm{D}(\mathrm{Rn}-\mathrm{G})+\mathrm{g} \mathrm{Cn}(\mathrm{u} 2 /(\mathrm{T}+273))(\text { es-ea })) /(\mathrm{D}+\mathrm{g}(1+\mathrm{Cd} \mathrm{u} 2))
$$

Here $\mathrm{Cn}$ and $\mathrm{Cd}$ are constants appropriate to 'short' grass. D is the slope of the saturated vapour pressure curve with respect to temperature, and $\mathrm{g}$ is the psychrometric constant. Net radiation (Rn), soil heat flux (G), D and g were calculated according to methods described by Allen et al. [12].

$\mathrm{Kc}_{\mathrm{c}}$ is the crop- and field-specific 'crop coefficient' appropriate to the irrigated field [16]. For the calculation of Kc the equation shown below (Equation 4) was used. This was developed for pastures in Australian conditions [30] using information from multiple seasons. The equation was validated for this study using the ET and NDVI measures from a recent Landsat scene taken over the study area:

$$
\mathrm{Kc}=1.33(\mathrm{NDVI}-0.1) ; \mathrm{NDVI}>0.2
$$

Pixels with NDVI below 0.2 were considered as non-active vegetation.

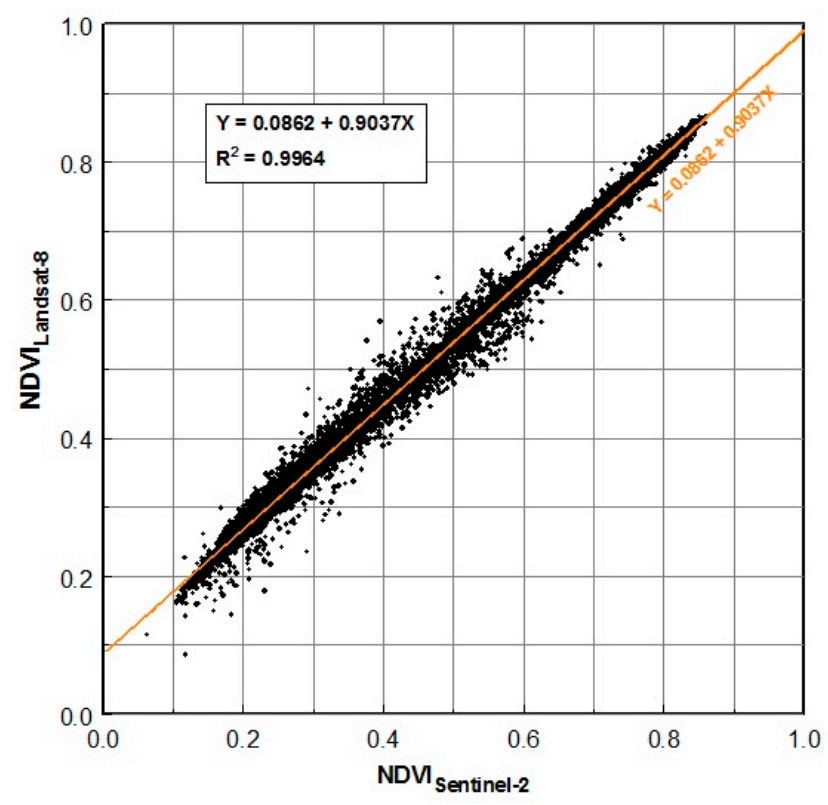

Figure 3. Inter-sensor NDVI comparison of Landsat- 8 and Sentinel-2 using synchronous images of 23 September and 12 December 2016, covering the Goulburn-Murray Irrigation District.

\subsection{NDVI-Dependent Soil Water Balance Estimates of Irrigation Water Requirement}

NDVI-dependent soil water balance calculations were carried out using the standard water balance equation below. In the equation, the daily increase in soil-stored water of a given soil volume (dS) is attributed to daily rainfall (RF) and irrigation (I). The losses in dS are attributed to evapotranspiration (ET), interception evaporation of rainfall from soil and plant surfaces (IE), and runoff and deep percolation $(R+D)$ :

$$
\mathrm{dS}=(\mathrm{I}+\mathrm{RF})-\mathrm{ET}-\mathrm{IE}-(\mathrm{R}+\mathrm{D})
$$

The increase in soil water on day, i, was calculated as follows:

$$
\mathrm{S}_{(\mathrm{i}+1)}=\mathrm{S}_{(\mathrm{i})}+\mathrm{dS}
$$


Analyses were conducted on notional volumes of irrigated soil, described by an allowable soil water deficit of $\mathrm{L}[\mathrm{mm}]$. Following the commonly accepted practice, $\mathrm{L}$ was calculated as the product of depth of crop root zone (zR) and the readily available soil water content (RAWC) in the root zone applicable to the irrigated area:

$$
\mathrm{L}=\mathrm{zR} \cdot \mathrm{RAWC}
$$

Vegetation water use is described by ET, which is equivalent to ETc in the present context, and was calculated by the standard Equation (2) above.

Irrigation soil water budgets for the summer period (1 December 2015-29 February 2016) were conducted on the assumption, $\mathrm{S}=\mathrm{L}$, on day 1 of the season. Adaptive, "Constant depth, variable frequency" irrigation events of depth, $\mathrm{L}$ [mm], were subsequently triggered on days whenever available soil water content in the nominal irrigation zone had fallen from the upper limit, $S=\mathrm{L}$, to the lower limit, $S=0$.

Intercepted rainfall, IE, was estimated as Class A pan evaporation (Epan) on days when RF > Epan, and as RF on days when Epan $<R F$ :

$$
\begin{gathered}
\mathrm{IE}=\mathrm{RF} ; \mathrm{RF}<\text { Epan } \\
\mathrm{IE}=\text { Epan; RF }>\text { Epan }
\end{gathered}
$$

Rainfall losses as runoff and/or deep drainage $(R+D)$ resulted when rainfall contributions to $S$ exceeded the upper storage limit, $\mathrm{S}=\mathrm{L}$. In those circumstances, ' $\mathrm{R}+\mathrm{D}^{\prime}$ was estimated as:

$$
(\mathrm{R}+\mathrm{D})=\mathrm{S}-\mathrm{L}
$$

And $\mathrm{S}$ was restored to the upper limit, $\mathrm{S}=\mathrm{L}$. IWR was calculated as the sum of the amounts of water required to replenish $S$ from values, $S=0$, to $S=L$.

Irrigation soil water balances varied with the proportion of vegetation cover (NDVI), through the effects on Kc (Equation (4)). For this study, analyses were conducted for the field/parcel specific value(s) of NDVI seen in summer image data. Analyses were also conducted over a range of values of $\mathrm{L}(20 \mathrm{~mm}<\mathrm{L}<50 \mathrm{~mm}$ ) to investigate the effects of potential combinations of irrigation system/soil type on estimates of IWR. The value, $\mathrm{L}=20 \mathrm{~mm}$, was chosen to represent centre pivot irrigation of pastures on 'light' (i.e., more sandy) soils, and a value, $\mathrm{L}=50 \mathrm{~mm}$, was adopted to represent surface irrigation of pastures grown on 'medium-heavy' (i.e., more loamy to clayey) soils. The value, $\mathrm{L}=50$ $\mathrm{mm}$, was adopted to describe irrigation water use over the study area (Figure 4). Estimates of IWR $(\mathrm{mm})$ were converted to $\mathrm{ML}$ to match the irrigation water delivery units. The general conversion formula used was: $100 \mathrm{~mm}=1 \mathrm{ML} / \mathrm{ha}$.

\subsection{Relative Irrigation Water Use (RIWU)}

Relative Irrigation Water Use (RIWU) is an irrigation performance indicator describing the practice of irrigation application at farm level. RIWU was calculated as the ratio of irrigation water supply (IWS) versus irrigation water requirement:

$$
\text { RIWU = IWS } / \text { IWR }
$$

This indicator was used as a measure of the ability of irrigators to ensure that the pastures are free of water stress. A value of 1 RIWU indicates the ideal situation when irrigators apply irrigation water as per crop/pasture requirement. Over-irrigation is described by RIWU > 1 and under-irrigation is indicated by RIWU $<1$. 


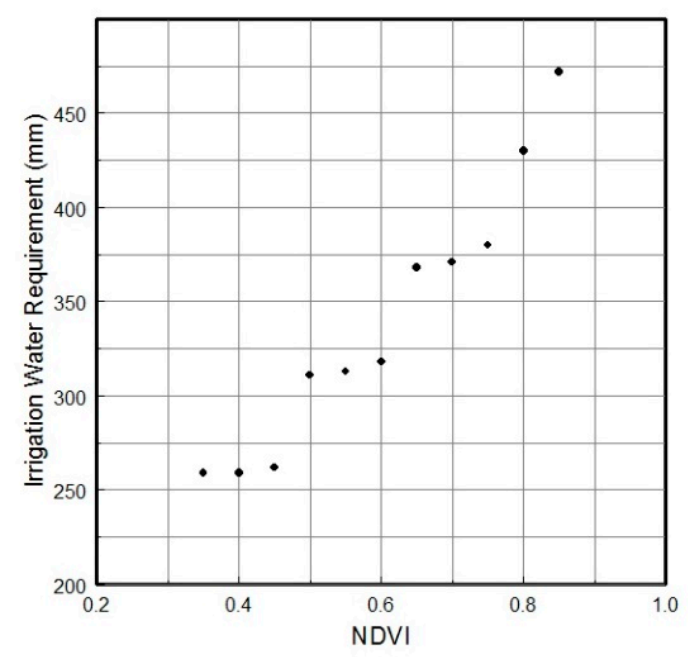

Figure 4. Water balance estimates of irrigation water requirement as per vegetation cover (NDVI) in summer 2015-2016.

\subsection{Total Irrigation Water Productivity (TIWP)}

The second irrigation performance indicator presented here is Total Irrigation Water Productivity (TIWP). This is a composite measure of two 'continuous' variables i.e., 'irrigation application' and 'pasture productivity'. For 'pasture productivity', NDVI was taken as a measure of yield potential of pastures on the basis of an established evidence of strong positive relationship between NDVI and pasture biomass [31]. Pasture productivity thus estimated was compared with the corresponding measures of RIWU. TIWP is presented here as a categorical measure assessing the pasture productivity classes (low/medium, high) against irrigation applications (low, optimal, excessive), as shown in Figure 5. The nominal threshold for the two productivity classes was taken as 0.65 NDVI based on local field experience. Thresholds for the irrigation intensity classes were taken as 0.5 and 1.5 RIWU on the basis of local knowledge of irrigation practices in the study area. If irrigators apply less than half of the required amount of irrigation (IWS/IWR $<0.5$ ), the situation may be called 'under-irrigation' classed here as 'low'. On the other hand, if irrigators apply $50 \%$ more irrigation (IWS/IWR > 1.5) than the required amount, the situation may be considered 'over-irrigation', classed here as 'excessive'.

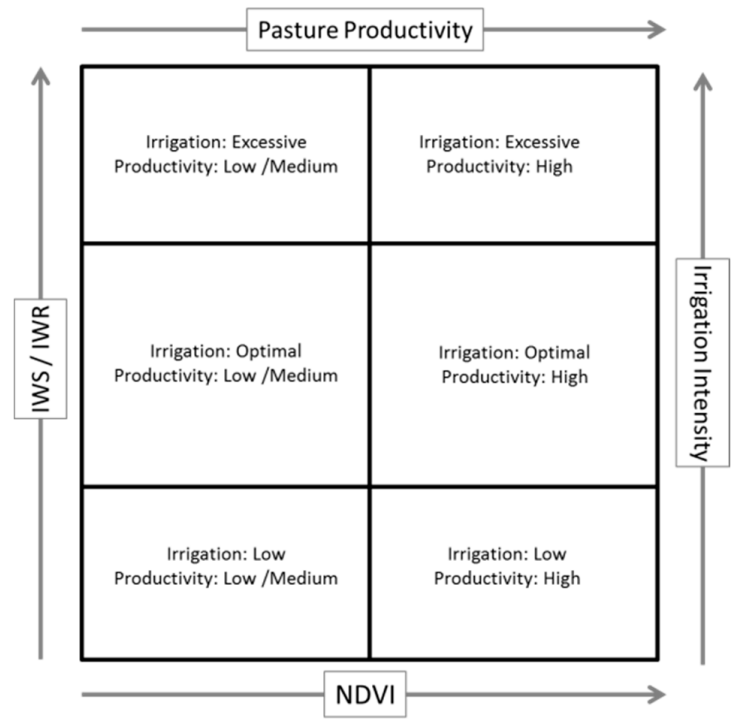

Figure 5. Diagram showing categories of total irrigation water productivity (TIWP) measure. 


\section{Results}

The majority of dairy farms (i.e., $79 \%$ ) in the study area had a relatively high vegetation cover in the summer season of 2015-2016, as denoted by high NDVI range of 0.5-0.7 (Figure 6). There were some instances (21\%) where mean farm-scale NDVI exceeded 0.7. As a consequence, crop/pasture water requirement varied widely across the farms (Figure 7). Farm-scale IWR varied from a minimum of about $280 \mathrm{~mm}$ to a maximum of about $445 \mathrm{~mm}$. The majority of IWR observations (98\%) were in the range of 300-390 $\mathrm{mm}$.

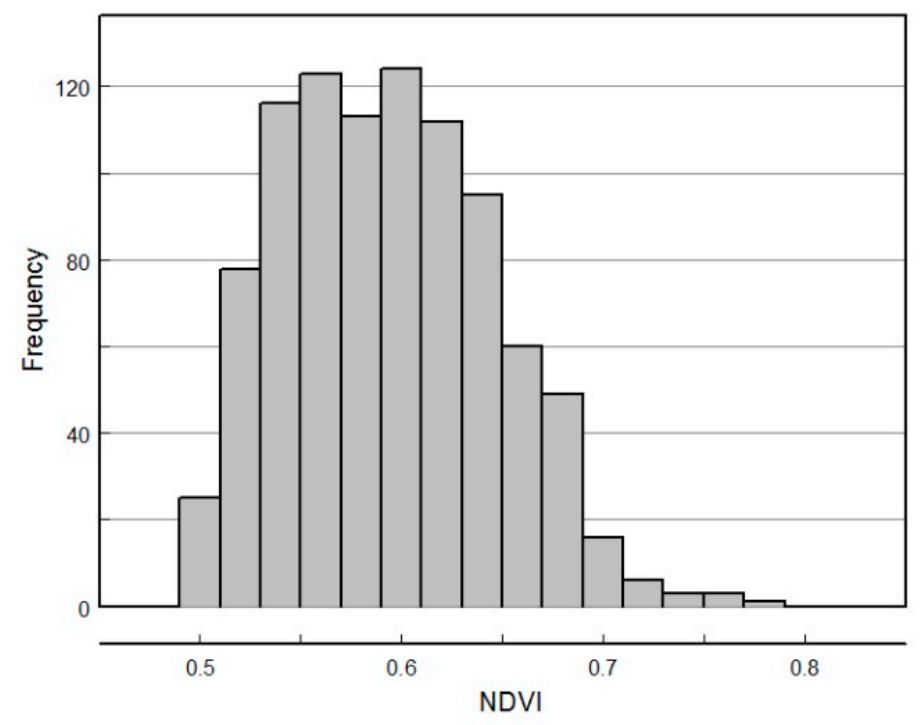

Figure 6. Frequency distribution of mean NDVI on dairy farms in the Goulburn-Murray Irrigation District in summer 2015-2016.

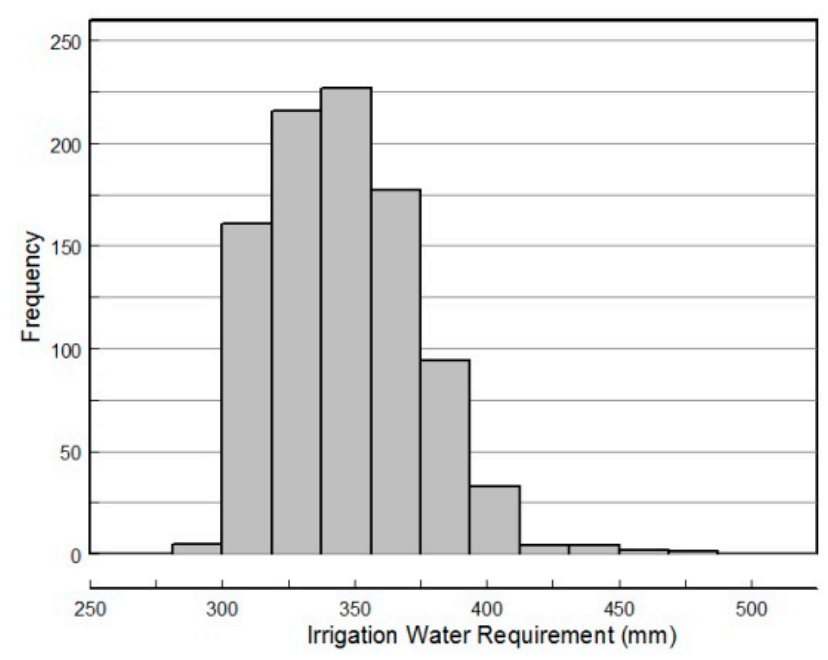

Figure 7. Frequency distribution of NDVI-dependent Irrigation Water Requirement (IWR) for the dairy farms in the Goulburn-Murray Irrigation District during summer 2015-2016.

\subsection{Regional Distribution of Relative Irrigation Water Use (RIWU)}

Figure 8 shows a positive relationship between surface water deliveries, and the NDVI-dependent water balance estimates of irrigation water requirement for the 924 dairy farms (shown by dots) investigated in this study. A large number of farms were under 200 ML IWR-IWS. The continuous diagonal line indicates where demand matches supply (IWR = IWS). Farms shown below the diagonal 
line generally indicate that irrigation is less than required, whereas the farms above the diagonal line indicate that irrigation exceeds requirement. In general, a high RIWU (IWS/IWR) value indicates a high amount of irrigation water delivered to a given farm as compared to the amount of water required for the pasture on that farm.

The regional distribution of relative irrigation water use (RIWU, Equation 10) is summarised in Figure 9. A slightly higher proportion of dairy farms (56\%) had RIWU of 1 or less, indicating the irrigation practice of either matching the requirement or under-watering. The RIWU value range of $0.5-1.5$ has been considered here as an optimal level of irrigation practice. The broken diagonal lines in Figure 8 show the range of optimal irrigation which encompasses about half of the dairy farms $(54 \%)$.

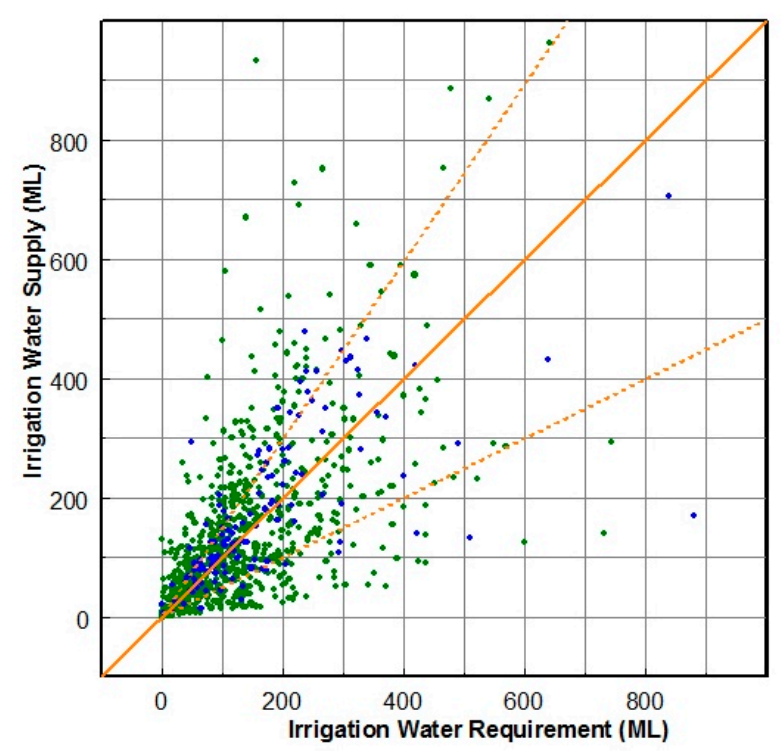

Figure 8. Regional relationship between irrigation water requirement (IWR) and irrigation water supply (IWS) at farm level during summer 2015-2016. Each dot represents a dairy farm. Green indicates low to medium pasture productivity (NDVI $<0.65$ ), whereas blue indicates higher productivity (NDVI $\geq$ 0.65). The continuous diagonal line shows the 1:1 relationship. The two broken lines show the limit of 'optimal' irrigation (IWS/IWR: 0.5-1.5).

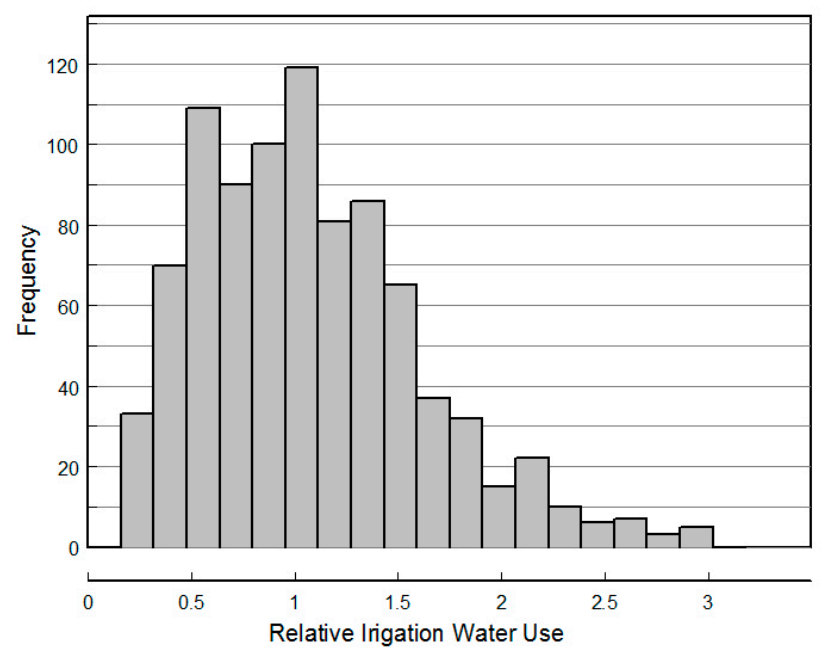

Figure 9. Frequency distribution of Relative Irrigation Water Use (RIWU) of the dairy farms in the Goulburn-Murray Irrigation District, summer 2015-2016. 


\subsection{Regional Distribution of Total Irrigation Water Productivity (TIWP)}

The regional overview of Total Irrigation Water Productivity (TIWP) on dairy farms during the peak irrigation season of summer 2015-2016 is presented in Figure 10. Here TIWP categories show the extent to which irrigators satisfied both productivity potential and water supply prerequisites. Observations in Figure 10 are summarised in Table 2. It is shown that relatively few dairy farms (3\%) fell in the category of high yield potential with excess water use, and very few $(1 \%)$ fell in the category of limited water supply to pastures of high yield potential. A relatively high number of farms fell in the category where excess water was supplied to pastures of low-medium yield potential $(27 \%)$, and farms where water supply compromised pastures with a sub-maximal vegetation status (15\%). Almost half the number of dairy farms (54\%) were providing an optimal level of irrigation, of which a larger proportion (43\%) was in the 'low-medium productivity' category and a small proportion (11\%) in the 'high productivity' category (Table 2).

Table 2. Summary of the distribution of dairy farms according to the categories of total irrigation water productivity (TIWP) in the Goulburn-Murray Irrigation Region.

\begin{tabular}{ccccc}
\hline \multirow{2}{*}{$\begin{array}{c}\text { Pasture Productivity } \\
\text { (NDVI) }\end{array}$} & \multicolumn{4}{c}{ Irrigation Intensity (Relative Irrigation Water Use) } \\
\cline { 2 - 5 } & Low (Suboptimal) & Optimal & Excessive (Supra-Optimal) & Total \\
\hline Low-Medium & $\mathbf{1 3 6}(\mathbf{1 5 \% )}$ & $\mathbf{3 9 8} \mathbf{( 4 3 \% )}$ & $\mathbf{2 5 2} \mathbf{( 2 7} \%)$ & $786(85 \%)$ \\
High & $\mathbf{1 2}(\mathbf{1 \% )}$ & $\mathbf{9 7 ( 1 1 \% )}$ & $\mathbf{2 9}(\mathbf{3} \%)$ & $138(15 \%)$ \\
Total & $148(16 \%)$ & $495(54 \%)$ & $281(30 \%)$ & $924(100 \%)$ \\
\hline
\end{tabular}

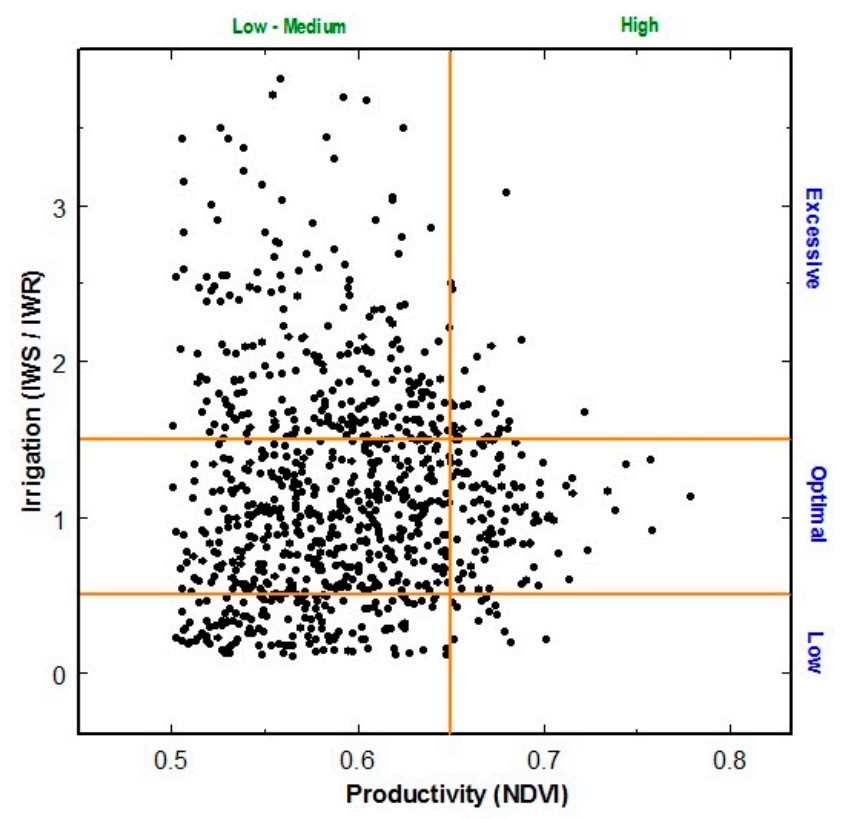

Figure 10. Diagram showing low-medium and high pasture productivity (NDVI) for Summer 2015-2016 (x-axis) against categories associated with low (sub), optimal, and excessive (supra) classes of IWS:IWR ratio (y-axis).

\section{Discussion}

This study was undertaken to demonstrate the application of new approaches based on satellite remote sensing with the aim of improving the measurement, monitoring and understanding of irrigation water use and water use productivity in regional Victoria, Australia. With a focus on dairy farms, this case study presents water use and water productivity for a selected season of summer 2015-2016 in the Goulburn-Murray Irrigation District, by combining satellite-based measures with weather and water delivery information. 
Farm management does have an impact on the health of pasture and sustainability of farm. However, irrigated dairy pastures in the study area are highly managed. From a sustainability point of view it is unlikely that farmers allow extensive grazing over the whole farm, or over a large part of a farm, in one instance. Grazing practices in the region are considered fairly uniform. Therefore, it is assumed that grazing did not have any significant effect in capturing farm level pasture status by satellite timing.

The investigation additionally aimed to acquaint potential end-users with the principles, methods and outputs of the new satellite-based procedures and to demonstrate the ability to address the data needs of multiple end-users including Catchment Management Authorities (CMAs), water providers (e.g., Goulburn-Murray Water), government agencies (e.g., DEDJTR, DELWP, MDBA), and irrigators. Data interests generally extend from those of water suppliers, who place a major emphasis on issues of supply adequacy (time and quantity), and the spatial uniformity of water supply. Irrigators are interested in an adequacy of supply consistent with the requirements of pasture/crop and on-farm production targets. The dual supply/productivity emphasis provided by the present study represents a key initial step towards meeting the information needs of multiple end-users with a stake in farm water use and irrigation water productivity.

The summary of outcomes, provided in Table 2 and Figure 10, identified six classes of irrigator performance based on two categories of productivity potential (i.e., low-medium, high) and three categories of adequacy of crop/pasture water supply (i.e., low, optimal, excessive). The analysis did not distinguish between on-farm or off-farm causes of the sub-optimal (low) supply, which requires further investigation. However, high water use on farms in the supra-optimal supply categories is potentially attributable to 'over-enthusiasm' on the part of irrigators. Alternatively, irrigators may be using water to compensate for disadvantaged soil conditions (e.g., light soils), which needs to be further investigated. The analysis otherwise quantifies irrigators whose water use is consistent with crop requirements (i.e., optimal water users). On- and off-farm water delivery/supply initiatives should clearly aim to maximise the number of irrigators in the optimal use category. A farm productivity perspective further requires that most of farmers should be in the category where optimal water use is combined with a high production potential. In this case, $43 \%$ of operators were found to be in this high productivity/optimal water use category, and $11 \%$ of operators were in the low-medium productivity/optimal water use category. Further investigations are warranted to determine (1) whether irrigator categories are consistent over time and in different seasonal conditions, (2) what the reasons are of over- and under-irrigation, and (3) what the factors are to achieve high productivity with optimal water use.

The satellite-based water balance approach applied in this study, and the two irrigation performance indicators (RIWU, TIWP) analysed here, provide a diagnostic framework that makes it possible to investigate the strength of region-specific relationships that describe the dependence of water use and productivity on-farm (e.g., light/heavy soil types), and/or off-farm factors (e.g., local/regional deficiencies in the irrigation supply system).

\section{Conclusions}

This study has demonstrated the application of Remote Sensing technology, in combination with weather and water delivery information, to derive two irrigation performance indicators i.e., Relative Irrigation Water Use (RIWU) and Total Irrigation Water Productivity (TIWP). About $54 \%$ of dairy farms in the summer of 2015-2016 in the Goulburn-Murray Irrigation District were optimally irrigated, whereas about $30 \%$ farms were over-irrigated. The prospective applications are warranted to investigate relationships between irrigation performance and variables that include soil types, regional water supply systems and the dependence of farm productivity on farm management. Such analyses will assist to clearly identify where significant improvements in efficient irrigation water use can be achieved. 
This study has described an integrated robust approach to irrigation water use assessment that addresses the following characteristics:

Accuracy: Utilization of remotely-sensed satellite data sets provides objective assessments on which to build confidence in the methodology.

Coverage: Presently resource satellites (e.g., Landsat-8, Sentinel-2), national weather agencies (Bureau of Meteorology, SILO) and water authorities (e.g., Goulburn-Murray Water contributing to Victorian Water Register) provide sufficient spatial and temporal coverage which is adequate for irrigation water assessment.

Repeatability: The methodology is repeatable with a high level of confidence which, to a great extent, is attributed to the provision of consistency and ongoing availability of essential data sets (satellite, weather and water supply).

Affordability: It is a recent development that all of the information (satellite, weather, water supply) required for irrigation assessment has been readily accessible and cost-neutral in almost all instances.

Acknowledgments: Victorian Department of Department of Environment, Land, Water and Planning provided financial support for this work.

Author Contributions: Des Whitfield provided conceptual framework and data analysis; Andy McAllister contributed to data collection, processing and interpretation; and Mohammad Abuzar carried out the image analysis and output generation.

Conflicts of Interest: Authors declare no conflict of interest.

\section{References}

1. Colaizzi, P.; Bliesner, R.; Hardy, L. A review of evolving critical priorities for irrigated agriculture. In World Environmental and Water Resources Congress 2008; American Society of Civil Engineers: Reston, VA, USA, 2008; pp. 1-15.

2. Food and Agriculture Organization (FAO). Aquastat Database. Available online: http://www.Fao.Org/nr/ water/aquastat/data (accessed on 28 June 2016).

3. Lorite, I.J.; Mateos, L.; Fereres, E. Evaluating irrigation performance in a Mediterranean environment: II. Variability among crops and farmers. Irrig. Sci. 2004, 23, 85-92. [CrossRef]

4. Levidow, L.; Zaccaria, D.; Maia, R.; Vivas, E.; Todorovic, M.; Scardigno, A. Improving water-efficient irrigation: Prospects and difficulties of innovative practices. Agric. Water Manag. 2014, 146, 84-94. [CrossRef]

5. Santos, C.; Lorite, I.; Tasumi, M.; Allen, R.; Fereres, E. Performance assessment of an irrigation scheme using indicators determined with remote sensing techniques. Irrig. Sci. 2010, 28, 461-477. [CrossRef]

6. Santos, C.; Lorite, I.J.; Tasumi, M.; Allen, R.G.; Fereres, E. Integrating satellite-based evapotranspiration with simulation models for irrigation management at the scheme level. Irrig. Sci. 2008, 26, 277-288. [CrossRef]

7. Burt, C.M.; Clemmens, A.J.; Strelkoff, T.S.; Solomon, K.H.; Bliesner, R.D.; Hardy, L.A.; Howell, T.A.; Eisenhauer, D.E. Irrigation performance measures: Efficiency and uniformity. J. Irrig. Drain. Eng. 1997, 123, 1943-4774. [CrossRef]

8. Ahadi, R.; Samani, Z.; Skaggs, R. Evaluating on-farm irrigation efficiency across the watershed: A case study of New Mexico's lower rio grande basin. Agric. Water Manag. 2013, 124, 52-57. [CrossRef]

9. Belaqziz, S.; Khabba, S.; Er-Raki, S.; Jarlan, L.; Le Page, M.; Kharrou, M.H.; Adnani, M.E.; Chehbouni, A. A new irrigation priority index based on remote sensing data for assessing the networks irrigation scheduling. Agric. Water Manag. 2013, 119, 1-9. [CrossRef]

10. Hellegers, P.G.J.; Soppe, R.; Perry, C.; Bastiaanssen, W.M. Remote sensing and economic indicators for supporting water resources management decisions. Water Resour. Manag. 2010, 24, 2419-2436. [CrossRef]

11. Doorenbos, J.; Pruitt, W.O. Guidelines for Predicting Crop Water Requirements, FAO Irrigation and Drainage Paper No 24; Food and Agriculture Organization (FAO): Rome, Italy, 1977.

12. Allen, R.G.; Pereira, L.S.; Raes, D.; Smith, M. Crop Evapotranspiration: Guidelines for Computing Crop Water Requirements, FAO Irrigation and Drainage Paper 56; Food and Agriculture Organization (FAO): Rome, Italy, 1998. 
13. Pereira, L.S.; Allen, R.G.; Smith, M.; Raes, D. Crop evapotranspiration estimation with FAO56: Past and future. Agric. Water Manag. 2015, 147, 4-20. [CrossRef]

14. Tasumi, M.; Allen, R.; Trezza, R.; Wright, J. Satellite-based energy balance to assess within-population variance of crop coefficient curves. J. Irrig. Drain. Eng. 2005, 131, 94-109. [CrossRef]

15. Whitfield, D.; Abuzar, M.; McAllister, A. Satellite-based assessments of irrigation water use by table grapes grown in the Robinvale District of SE Australia. In Proceedings of the 7th International Table Grape Symposium, Victoria, Australia, 11-14 November 2014; pp. 106-108.

16. Allen, R.G.; Tasumi, M.; Trezza, R. Satellite-based energy balance for mapping evapotranspiration with internalized calibration (METRIC)—Model. J. Irrig. Drain. Eng. 2007, 133, 380-394. [CrossRef]

17. D'Urso, G.; Calera Belmonte, A. Operative approaches to determine crop water requirements from earth observation data: Methodologies and applications. In Earth Observation for Vegetation Monitoring and Water Management; American Institute of Physics: College Park, MD, USA, 2006; Volume 852, pp. 14-25.

18. D’Urso, G.; Richter, K.; Calera, A.; Osann, M.A.; Escadafal, R.; Garatuza-Pajan, J.; Hanich, L.; Perdigão, A.; Tapia, J.B.; Vuolo, F. Earth observation products for operational irrigation management in the context of the pleiades project. Agric. Water Manag. 2010, 98, 271-282. [CrossRef]

19. Allen, R.G.; Tasumi, M.; Morse, A.; Trezza, R.; Kramber, W.; Lorite, I. Satellite-based energy balance for mapping evapotranspiration with internalized calibration (METRIC)—Applications. J. Irrig. Drain. Eng. 2007, 133, 395. [CrossRef]

20. Bastiaanssen, W.G.M.; Menenti, M.; Feddes, R.A.; Holtslag, A.A.M. A remote sensing surface energy balance algorithm for land (SEBAL). 1. Formulation. J. Hydrol. 1998, 212-213, 198. [CrossRef]

21. Tasumi, M.; Allen, R.G.; Trezza, R. Calibrating satellite-sased vegetation indices to estimate evapotranspiration and crop coefficients. In Proceedings of the USCID Water Manangement Conference, Biose, Idaho, 25-28 October 2006; United States Committee on Irrigation and Drainage: Denver, CO, USA, 2006.

22. Allen, R.G.; Pereira, L.S.; Howell, T.A.; Jensen, M.E. Evapotranspiration information reporting: I. Factors governing measurement accuracy. Agric. Water Manag. 2011, 98, 899-920. [CrossRef]

23. Rafn, E.B.; Contor, B.; Ames, D.P. Evaluation of a method for estimating irrigated crop-evapotranspiration coefficients from remotely sensed data in idaho. J. Irrig. Drain. Eng. 2008, 134, 722-729. [CrossRef]

24. Pôças, I.; Paço, T.A.; Paredes, P.; Cunha, M.; Pereira, L.S. Estimation of actual crop coefficients using remotely sensed vegetation indices and soil water balance modelled data. Remote Sens. 2015, 7, 2373-2400. [CrossRef]

25. Campos, I.; Boteta, L.; Balbontín, C.; Fabião, M.; Maia, J.; Calera, A. Remote sensing based water balance to estimate evapotranspiration and irrigation water requirements. Case study: Grape vineyards. In The Use of Remote Sensing and Geographic Information Systems for Irrigation Management in Southwest Europe; Erena, M., López-Francos, A., Montesinos, S., Berthoumieu, J.P., Eds.; CIHEAM/IMIDA/SUDOE Interreg IVB (EU-ERDF): Zaragoza, Spain, 2012; Volume 67, pp. 85-94.

26. SILO Climate Data. Available online: www.longpaddock.qld.gov.au/silo/ (accessed on 6 August 2017).

27. Victorian Water Register. Available online: www.waterregister.vic.gov.au (accessed on 6 August 2017).

28. Morse-McNabb, E.M.; Sheffield, K.; Clark, R.; Lewis, H.; Robson, S.; Cherry, D.; Williams, S. Data from: VLUIS, a Land Use Data prOduct for Victoria, Australia, Covering 2006 to 2013; Dryad Data Repository: Durham, NC, USA, 2015.

29. United States Geological Survey. Landsat 8 (L8) Data Users Handbook; United States Geological Survey: Sioux Falls, SD, USA, 2015.

30. Whitfield, D.A.; McAllister, M.; Abuzar, K.; Sheffield, M.; O'Connell, M.; McClymont, L. Measurement, Monitoring and Reporting Systems for Improved Management of Farm and Regional Water Resources in Australia; Department of Primary Industries, State of Victoria: Tatura, Victoria, Australia, 2010.

31. Prabhakara, K.; Hively, W.D.; McCarty, G.W. Evaluating the relationship between biomass, percent groundcover and remote sensing indices across six winter cover crop fields in Maryland, United States. Int. J. Appl. Earth Obs. Geoinf. 2015, 39, 88-102. [CrossRef]

(C) 2017 by the authors. Licensee MDPI, Basel, Switzerland. This article is an open access article distributed under the terms and conditions of the Creative Commons Attribution (CC BY) license (http:/ / creativecommons.org/licenses/by/4.0/). 